\title{
Transplantation of Fetal CNS Tissue Into the Peripheral Nervous System: A Model to Study Aberrant Changes in the Neuronal Cytoskeleton
}

\author{
Laurie C. Doering \\ Department of Biomedical Sciences, Division of Anatomy, \\ McMaster University, Hamilton, Ontario, L8N 3Z5, Canada
}

\begin{abstract}
Defined regions (septum, substantia nigra) of the embryonic central nervous system (CNS) were transplanted into the sciatic nerves of young adult rats. Immunocytochemical techniques were used to examine the expression of neurotransmitter related enzymes and neuronal cytoskeletal proteins in the grafts.

The origin of the septal grafts was confirmed by immunoreactivity in neurons to choline acetyltransferase and the $\beta$-nerve growth factor receptor (192-IgG). In substantia nigra grafts, neuronal perikarya and processes were identified with an antibody directed against tyrosine hydroxylase. Typical spatial distributions of phosphorylated $\left(M_{r} 200,000\right)$ and non-phosphorylated $\left(M_{r} 168,000 \& 200,000\right)$ neurofilaments were observed in the short term (1-2 months) grafts with the monoclonal antibodies RT97 and SMI-32 respectively. Dense dendrite arbors and neuronal cell bodies were immunostained with an antibody that recognizes a high molecular weight microtubule associated protein (MAP2).

In the long term (1 year) transplants, prominent cytoskeletal changes in the somata, axons and dendrites of neurons were evident.
\end{abstract}

Reprint address:

Dr. L.C. Doering

Division of Anatomy

Faculty of Health Sciences, HSC 1R1

McMaster University

1200 Main Street West

Hamilton, Ontario L8N 3Z5

Canada
The cells showed a shift in phosphorylated neurofilament staining from the axon to the soma accompanied by a reduction in axonal immunoreactivity in the adjacent neuropil, Other abnormal features included swollen perikarya, hypertrophied axonal segments and short segments of kinked axons. Regression of the dendrite trees in the long standing grafts was also apparent when sections were reacted with the MAP2 antibody.

These experiments indicate that grafted fetal neurons, isolated in the peripheral nervous system, differentiate and express markers like their counterparts in situ. After extended time periods under these circumstances, cytoskeletal modifications become apparent in the neurons. These aberrant changes are similar to morphological characteristics associated with aging and neurodegenerative disorders. This experimental paradigm offers a new approach to study cytoskeletal disturbances in neurons and provides a unique opportunity to examine conditions that may modulate the abnormal changes.

Key words: Rat, peripheral nerve, graft, neurofilament, microtubule associated protein, immunocytochemistry, cytoskeleton, aging, dendrite.

\section{INTRODUCTION}

Regions of the embryonic central nervous system (CNS) have a remarkable potential to differentiate, grow and function subsequent to transplantation in the CNS. A number of conditions have been developed to obtain a high and 
reliable level of graft survival and growth (see review by Björklund and Stenevi /5/). In addition, sites outside the central neuraxis can be used to support the growth of embryonic neural tissue. In particular, the anterior chamber of the eye /41/ and the peripheral nervous system (PNS) $/ 1,4,46 /$ have been used to study specific regions in isolation from the CNS.

Based on the initial observations of filamentous changes in telencephalon subsequent to transplantation within sciatic nerves $/ 15 /$, this CNS-PNS paradigm has been actively studied to examine the cytoskeletal profiles in a number of defined regions of the CNS. In consideration of the neural centers prominently affected by certain neurodegenerative diseases, the analogous regions of the rat brain have been implanted into the PNS to assess changes in the neuronal cytoskeletal framework.

In this paper, neurons in septal and substantia nigra grafts are shown to survive in the PNS and express markers like their counterparts in vivo. The spatial distributions of the microtubule associated protein termed MAP2 and phosphorylated and non-phosphorylated neurofilament proteins were studied by indirect immunofluorescence. After long periods of graft survival, abnormal immunoreactivity to these cytoskeletal proteins was evident in neurons. The types of cytoskeletal changes are illustrated and discussed with reference to other systems that show similar changes.

\section{MATERIALS AND METHODS}

\section{Dissection of fetal CNS}

Timed pregnant Lewis rats were used as the source of fetal tissue. The rats were injected with a lethal dose of sodium pentobarbital (Somnotol) and the embryos taken on embryonic day 15 to achieve optimal survival of the CNS primordium /51/. Fine forceps were used to dissect the septum from the basal forebrain region and the substantia nigra from the ventral mesencephalon in sterile lactated Ringer's solution.

\section{Fetal transplants to sciatic nerves}

In young female Lewis rats (approximately 200 grams) the sciatic nerve trunk was transected about $0.5 \mathrm{~cm}$ from the spinal cord and the severed ends tied with suture 1 week previous to the grafting procedure. This initial operation clears the majority of host peripheral axons from the sciatic nerves and creates a favorable substratum for introduction of the embryonic tissue.

The recipient nerves were prepared for transplantation by an incision $(2.0 \mathrm{~mm})$ of the epineurium. Single grafts of septum $(n=12)$ and substantia nigra $(n=18)$ were aspirated into the glass needle tip of a tuberculin syringe and injected into the distal aspect of the sciatic nerves. The epineurium was then closed with 10-0 suture and the overlying muscles and skin were sutured. Half of the animals for each graft type were analyzed after 1-2 months (short term) and the remaining animals were studied after 1 year of survival.

\section{Immunocytochemical procedures}

Anesthetized host animals were initially perfused with cold saline and followed by $4.0 \%$ paraformaldehyde in $0.1 \mathrm{M}$ phosphate buffer. The sciatic nerves were dissected and post-fixed in $4.0 \%$ paraformaldehyde at $4^{\circ} \mathrm{C}$ overnight. The following morning the nerves were frozen in 2methyl butane cooled to $-55^{\circ} \mathrm{C}$. Longitudinal sections of the graft-nerve complex were cut $10 \mu \mathrm{m}$ thick on a cryostat and collected in $0.01 \mathrm{M}$ phosphate buffered saline (PBS). Sections were initially floated in $3.0 \%$ bovine serum albumin to reduce non-specific binding of the antibody immunoglobulins. Free floating sections were then rinsed with PBS and incubated overnight at $4^{\circ} \mathrm{C}$ with primary antibodies against the phosphorylated $M_{r} 200,000$ neurofilament unit (RT97), the non-phosphorylated $M \quad 168,000$ and 200,000 neurofilament protein (SMI-32), microtubule associated protein 2 (MAP2), tyrosine hydroxylase (TH), choline acetyltransferase (ChAT) and the rat $\beta$-nerve growth factor receptor (192-IgG). All antibodies have been previously described and the epitopes they recognize have been determined: RT97 /27/, SMI-32 /37,53/, MAP2 /58/, $\mathrm{TH} / 47 /$, ChAT /3,6/, 192-IgG /9,55/.

Subsequent to incubation with the primary monoclonal antibodies, the sections were thoroughly rinsed and reacted in goat anti-mouse IgG secondary antibodies conjugated to fluoroscein (Jackson Immunoresearch Laboratories 
Inc.). For the sections reacted with the polyclonal ChAT antisera, a goat anti-rabbit IgG linked to fluorescein was used. Control sections were checked by substituting normal serum for the primary antibodies and by the omission of the primary antibodies from the reaction. No specific immunofluoroscence was observed in the control sections.

For microscopic observation of the grafts, the sections were placed on glass microscope slides, rinsed with distilled $\mathrm{H}_{2} \mathrm{O}$ and completely dried. The sections were then coated with a 1:1 ratio of glycerol and sodium carbonate buffer ( $\mathrm{pH} 9.0)$ and coverslipped. The buffer contained $0.04 \%$ pphenylenediamine to reduce the fading effect of the UV light on the fluorescent probe.

\section{RESULTS}

\section{Expression of neurotransmitter related enzymes and the NGF-receptor}

In short term (1-2 months) septal grafts, groups of neurons were immunoreactive to the choline acetyltransferase (ChAT) antibody (Fig. 1a). The majority of the positive neurons were bipolar in shape. Staining was strong in the cell body and proximal segments of the processes. Lightly labeled delicate fibers in the neuropil were also visible in some areas of the grafts.

The 1 month old substantia nigra implants consisted of numerous tyrosine hydroxylase (TH) positive neurons (Fig. 1b). Surrounding networks of processes were intensely immunofluorescent. No cells or extracellular components of the host peripheral nerves reacted with the $\mathrm{TH}$ or ChAT antibody.

Nerve sections reacted with the nerve growth factor (NGF) receptor antibody (192-IgG) showed intense immunoreactivity in the Schwann cell columns (Fig. 1c). The boundaries of the grafts were sharply defined in the peripheral nerve matrix. In the septal grafts, neurons and fibers were labeled with the 192-IgG monoclonal antibody (Fig. 1d). The cellular pattern of immunolabeling was typical for basal forebrain neurons in situ. Strong immunofluorescent granules of different sizes in the perinuclear region and punctate marking of the processes characterized these $192-1 \mathrm{gG}$ positive neurons.

\section{Distribution of phosphorylated and non- phosphorylated neurofilaments}

Short term: The $M_{r} 200,000$ phosphorylated neurofilament antibody (RT97) defined dense networks of axons in the short term grafts. The RT97 staining characteristics (density of axons, directional patterns) varied according to the type of transplant (Figs. 2a,b and 3a). In the young grafts, expression of the RT97 epitope in neuronal perikarya was seen in the septum, but not in the substantia nigra. Regenerative and/or degenerative axons of peripheral origin were evident around the perimeter of the grafts. These peripheral axons were easily distinguished by their large diameter and uniform direction, i.e., parallel to the Schwann cell columns.

Similarly, the antibody to the non-phosphorylated neurofilament (SMI-32) outlined the extent of the grafts within the peripheral nerves. Subsets of neuronal perikarya and dendrites in the septal and nigral grafts were labeled with the SMI-32 (Figs. 2c and 3b). The largest stained neurons were intensely fluorescent. In contrast, smaller neurons were identified by weaker fluorescence in the somata. A population of the peripheral host axons also expressed the epitope for the SMI-32 antibody.

Long term: In addition to graft shrinkage, distinct differences in immunostaining were apparent in both types of the aged (1 year) transplants (Fig. 4). In sections reacted with the RT97 a reduction in axonal density was observed in many regions of the grafts. Numerous perikarya in septal and substantia nigra grafts showed strong RT97 immunoreactivity. The reversal in staining from the distal axon segments to the cell body and the dendrite shafts was accompanied by a loss of staining in the adjacent neuropil. In certain cases, neurofilaments in the axons and in the cell bodies were tortuous and disorganized; other neurons were characterized by a granular type of immunostaining in the somata (Fig. 4e). In some transplants, very short segments of kinked axons were apparent (Fig. 4d). Other prominent changes included swollen axon profiles and end-bulb swellings (Fig. 4f).

Aberrant SMI-32 immunoreactivity was also seen in the 1 year old grafts. Rather than a uniform distribution of labeled neuronal processes 


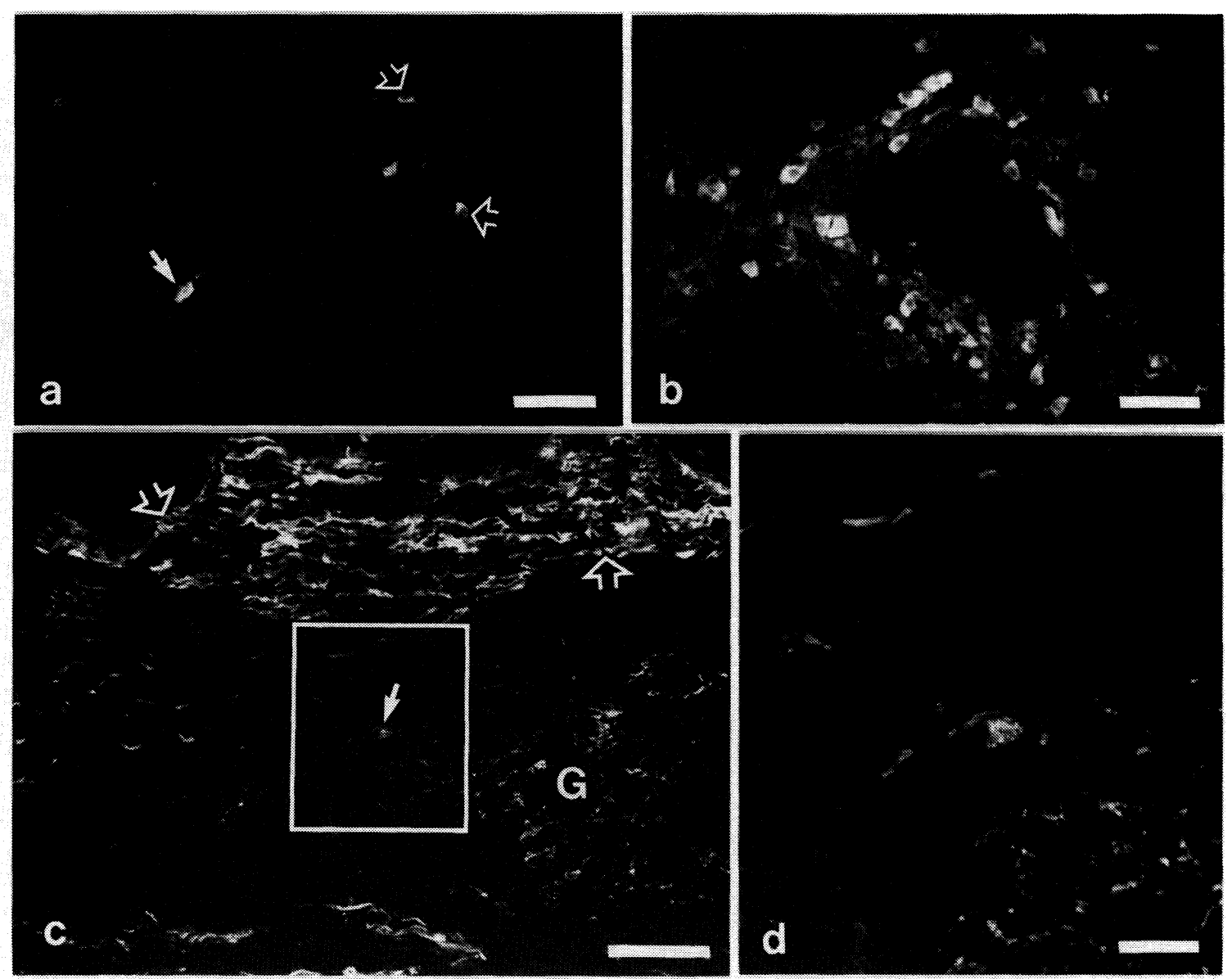

Fig. 1: Expression of neurotransmitter related enzymes and the $\beta$-NGF receptor in the CNS-PNS graft complex.

(a) Low magnification of ChAT staining in a one month old septal graft. Neuronal cell bodies (open arrows) are intensely fluorescent. Solid arrow shows a bipolar ChAT positive neuron with delicate processes.

(b) Portion of a one month old substantia nigra graft reacted with the TH monoclonal antibody. Perikarya and dense networks of processes characteristic of fine branching dendrites are labeled.

(c) Micrograph of the peripheral nerve-septal graft interface stained with the 192-lgG. Strong immunostaining in the Schwann cell columns (open arrows) contrasts with the delicate 192-lgG positive processes in the graft (G). Solid arrow points to a positive neuron in the graft.

(d) Neuron in Fig. 1c magnified to show the typical granular expression of the rat NGF receptor epitope identified by the 192-lgG.

Scale bar for Figs. $1 \mathrm{a}, \mathrm{b}$ and $\mathrm{c}=75 \mu \mathrm{m}$, for $1 \mathrm{~d}=20 \mu \mathrm{m}$.

throughout the transplants, dense aggregates of processes were surrounded by completely negative areas of SMI-32 immunoreactivity. Some of the SMI-32 labeled neurons appeared abnormally large and contained circular bands of neurofilaments that were strongly stained in the perimeter of the somata.

\section{Microtubule associated protein (MAP2)}

Short term: The antibody to the microtubule associated protein designated MAP2 (originally termed MAP 2.3) clearly outlined the perimeter of the substantia nigra and septal grafts within the host peripheral nerves. There was no immunoreactivity to this antibody in the host sciatic nerves. The interface of the graft dendrites with the peripheral nerve matrix was sharply defined. It was difficult to distinguish the shape of the dendrite arbors in many areas of the short term transplants as a result of limited section thick- 


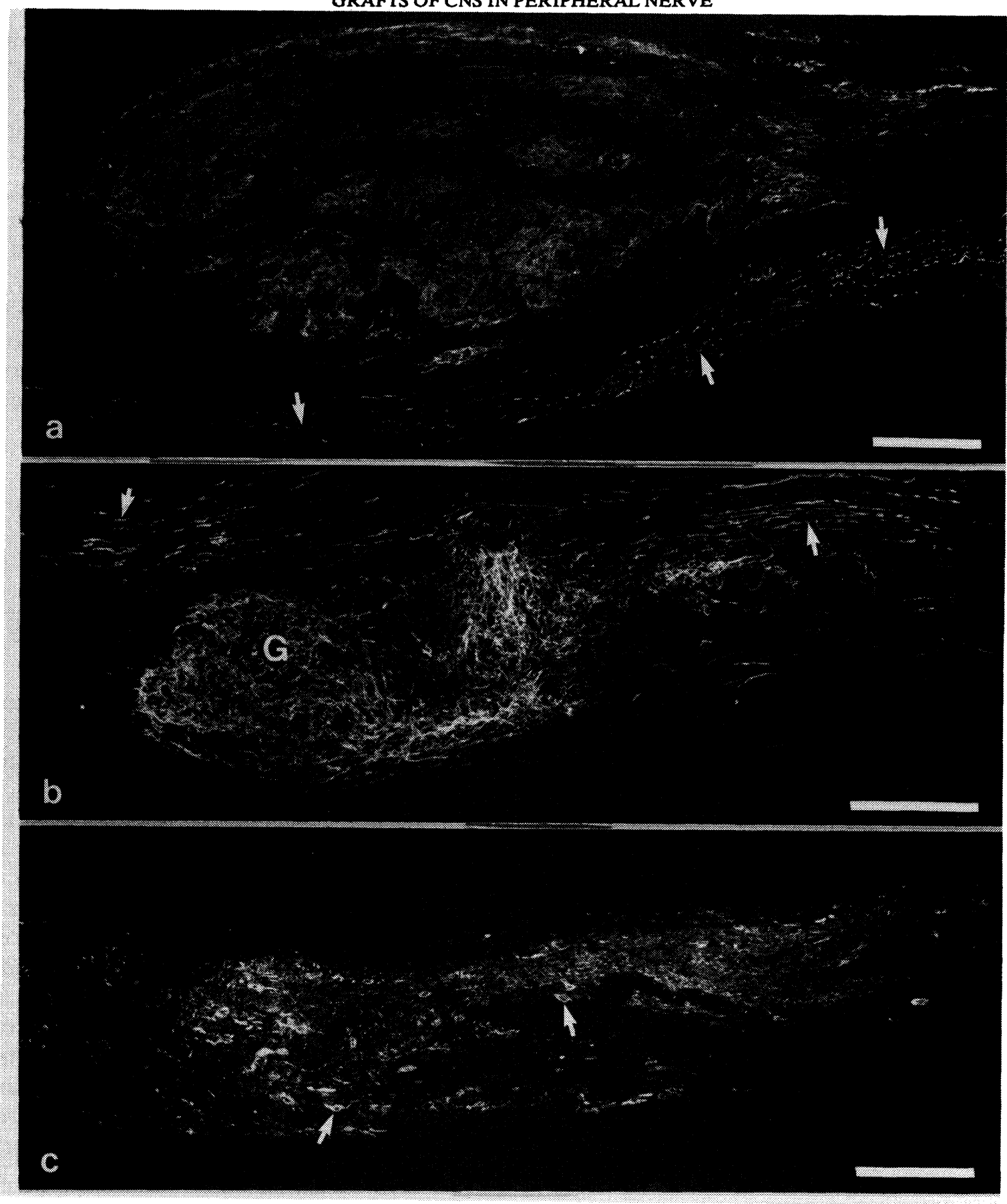

Fig. 2: Indirect immunofluorescence of phosphorylated (RT97) and non-phosphorylated (SMI-32) neurofilament patterns in short term grafts. Longitudinal sections of the graft-nerve composite are shown.

(a) Appearance of RT97 immunostaining in a one month old septal graft that has distended the sciatic nerve. Profiles of fine axonal processes are distributed in all areas of the transplant. Labeled peripheral axons are indicated by arrows.

(b) A two month old substantia nigra graft (G) in the sciatic nerve. Swirls of RT97 positive processes contrast with the regenerative peripheral host axons (arrows). Compare pattern of immunoreactivity with Fig. 2 a. (c) Example of a one month old substantia nigra graft reacted with the monoclonal antibody SMl-32. Arrows
mark neuronal perikarya.

Scale bar for Figs. $2 \mathrm{a}, \mathrm{b}$ and $\mathrm{c}=250 \mu \mathrm{m}$. 


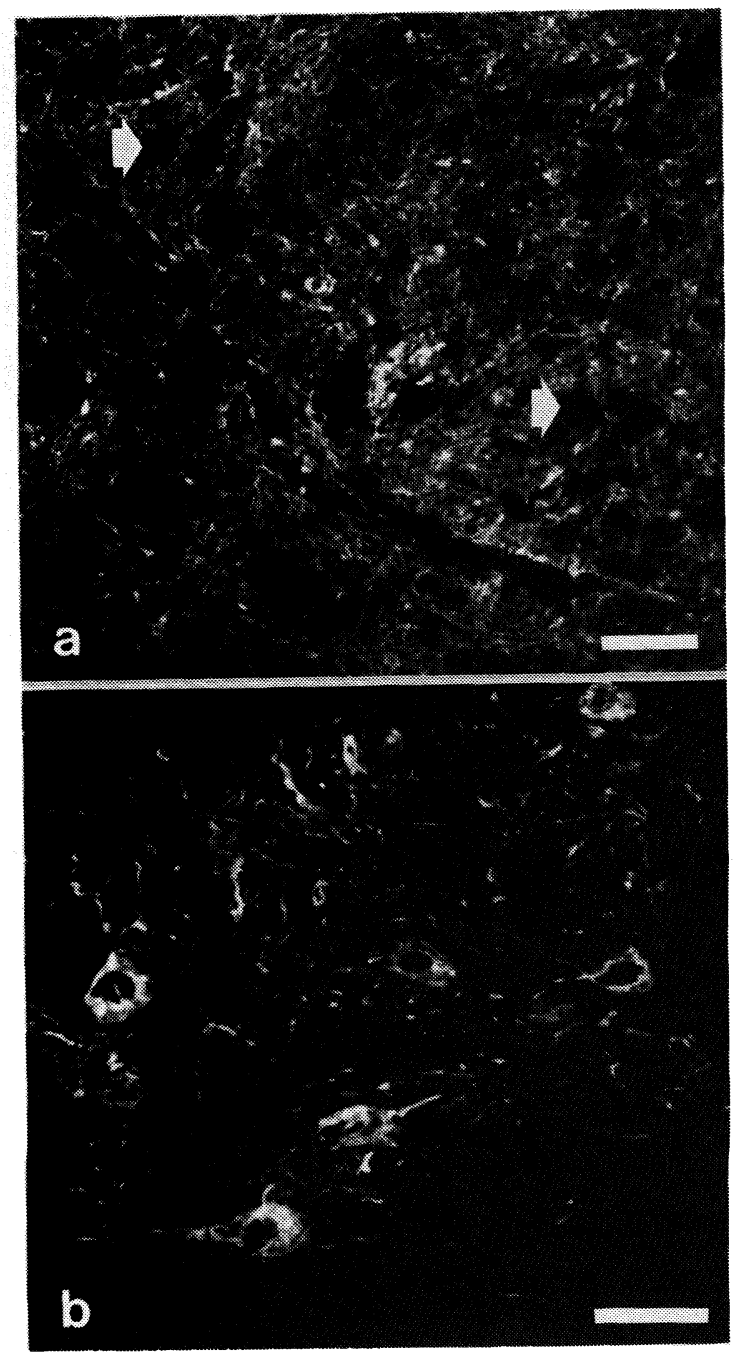

Fig. 3: Appearance of normal RT97 and SMI-32 immunolabeling in short term grafts.

(a) High magnification of a one month old septal graft reacted with the monoclonal antibody RT97. Fine axonal processes contrast with RT97 negative perikarya indicated by the arrows.

(b) Area of a two month old substantia nigra graft showing sites of immunofluorescence to the antibody SMI-32. Characteristic staining of the neuronal somata and sections of the dendrites are evident.

Scale bar for Figs. $3 a$ and $b=50 \mu \mathrm{m}$.

ness and the high density of stained processes (Fig. 5a). However, in certain regions not tightly packed with processes, arbors in their entirety could be seen. For example, in substantia nigra grafts, neurons with elongated narrow dendritic fields could be identified (Fig. 5b). Neuronal somas were also immunolabeled with this antibody.

Long term: Dendrite immunofluorescence patterns in both types of the long standing grafts were considerably different in appearance. In addition to a reduction in immunoreactivity (Fig. 5c), some neurons had only a short, single dendritic shaft with few or no secondary branches (Fig. 5c). Extensive hypertrophy of the perikarya and irregular somato-dendritic contours were common (Fig. 5d). The dendrites of some neurons appeared swollen and truncated. These disturbances in dendrite morphology were not present in the young grafts.

\section{DISCUSSION}

\section{Application of immunocytochemistry to study the cytoskeleton}

Immunocytochemistry has proven to be a very useful technique to study the temporal regulation and distribution of specific proteins (e.g., neurofilaments, phosphoproteins, tau and high molecular weight MAPs) in the developing and adult nervous system $/ 21,23,26,35 /$. Based on immunohistochemical results, certain cytoskeletal proteins integral to neuronal form and function /36/ have been shown to be differentially located in the dendrites, axons and somata of neurons $17,39,43 /$. Phosphorylated and non-phosphorylated neurofilament proteins represent a prominent example of asymmetric distribution in the neuron. Under normal circumstances, high molecular weight phosphorylated neurofilaments are found in the distal part of the axon and nonphosphorylated neurofilaments are located in the proximal axonal segments, dendrites and perikarya $/ 53 /$. When these same antibodies are applied to sections of brain affected by Alzheimer's or Parkinson's disease, abnormal patterns of immunoreactivity can be identified that offer important insights into the nature and extent of the cytoskeletal disturbances $/ 2,54,57 /$.

\section{Changes in distribution of the phosphorylated neurofilament epitope}

A primary cytoskeletal change in the present 

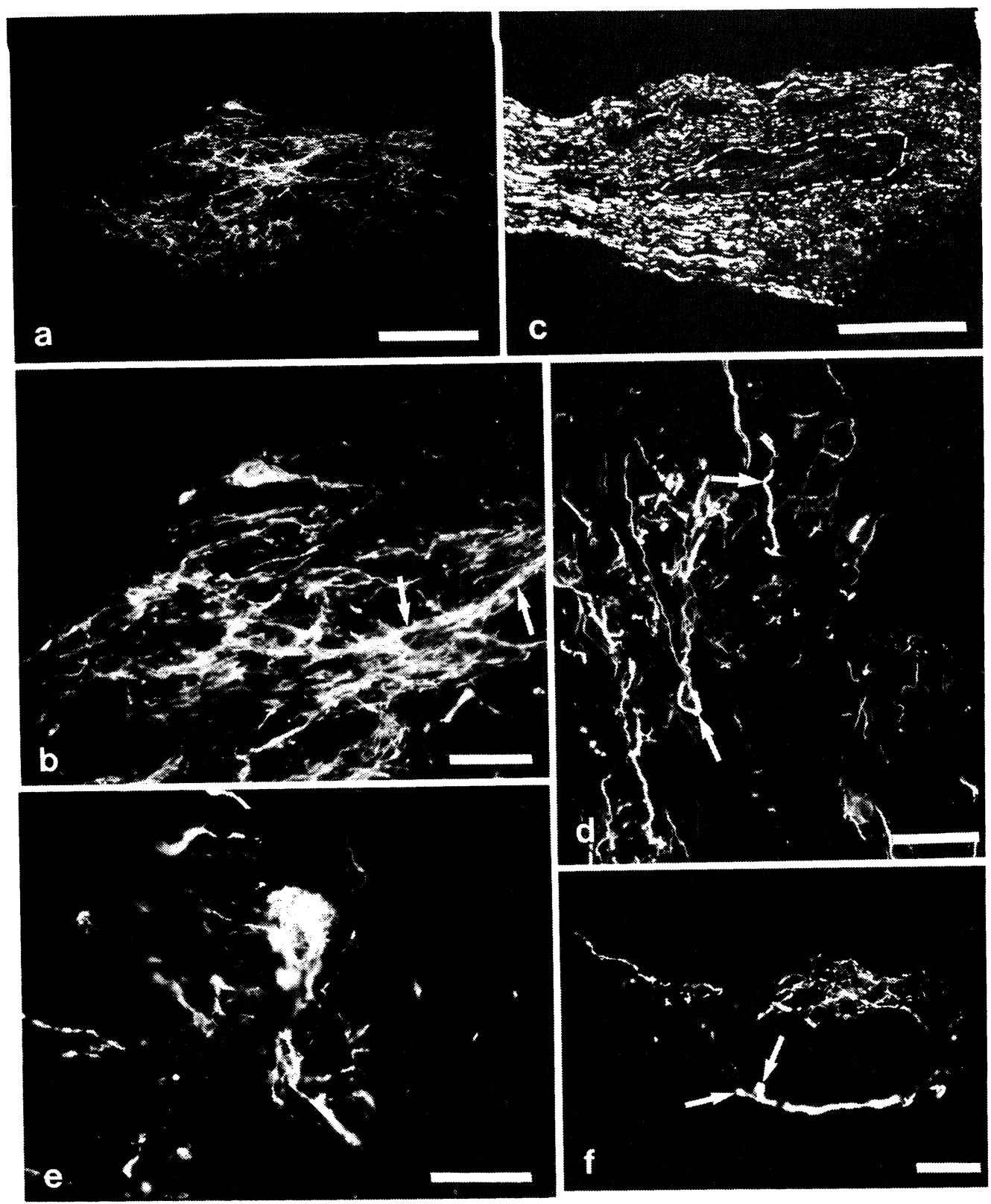

Fig. 4: Abnormal neurofilament (RT97) staining in long term implants.

(a) Low magnification of a one year old septal transplant. Neuron with prominent perikaryal immunoreactivity is located at the perimeter of the graft. Compare graft size and loss of axonal immunostaining with Fig. 2a. Scale bar $=200 \mu \mathrm{m}$.

(b) Upper part of graft in Fig. 4a enlarged to show the neuron with abnormal neurofilaments in the cell body. Note the presence of thick axons (arrows). Scale bar $=50 \mu \mathrm{m}$.

(c) Low magnification of a small one year old substantia nigra graft. Dashed line marks the boundaries of the transplant. Numerous regenerative profiles of peripheral axons surround the graft. Compare reduced size of this graft with Fig. $2 \mathrm{~b}$. Scale bar $=250 \mu \mathrm{m}$.

(d) Loss of normal RT97 staining in the neuropil of a one year old graft of substantia nigra. Profiles of short segments of kinked axons (arrows) are evident. Scale bar $=50 \mu \mathrm{m}$.

(e) Neuron in a one year old septal graft with aberrant perikaryal immunoreactivity to the phosphorylated $\mathrm{Mr}_{r}$ 200,000 neurofilament unit. Scale bar $=30 \mu \mathrm{m}$.

( $f$ ) Swollen axon with end-bulb terminations (arrows) contrasts with delicate RT97 positive axons in the neuropil of a substantia nigra implant. Scale bar $=20 \mu \mathrm{m}$. 

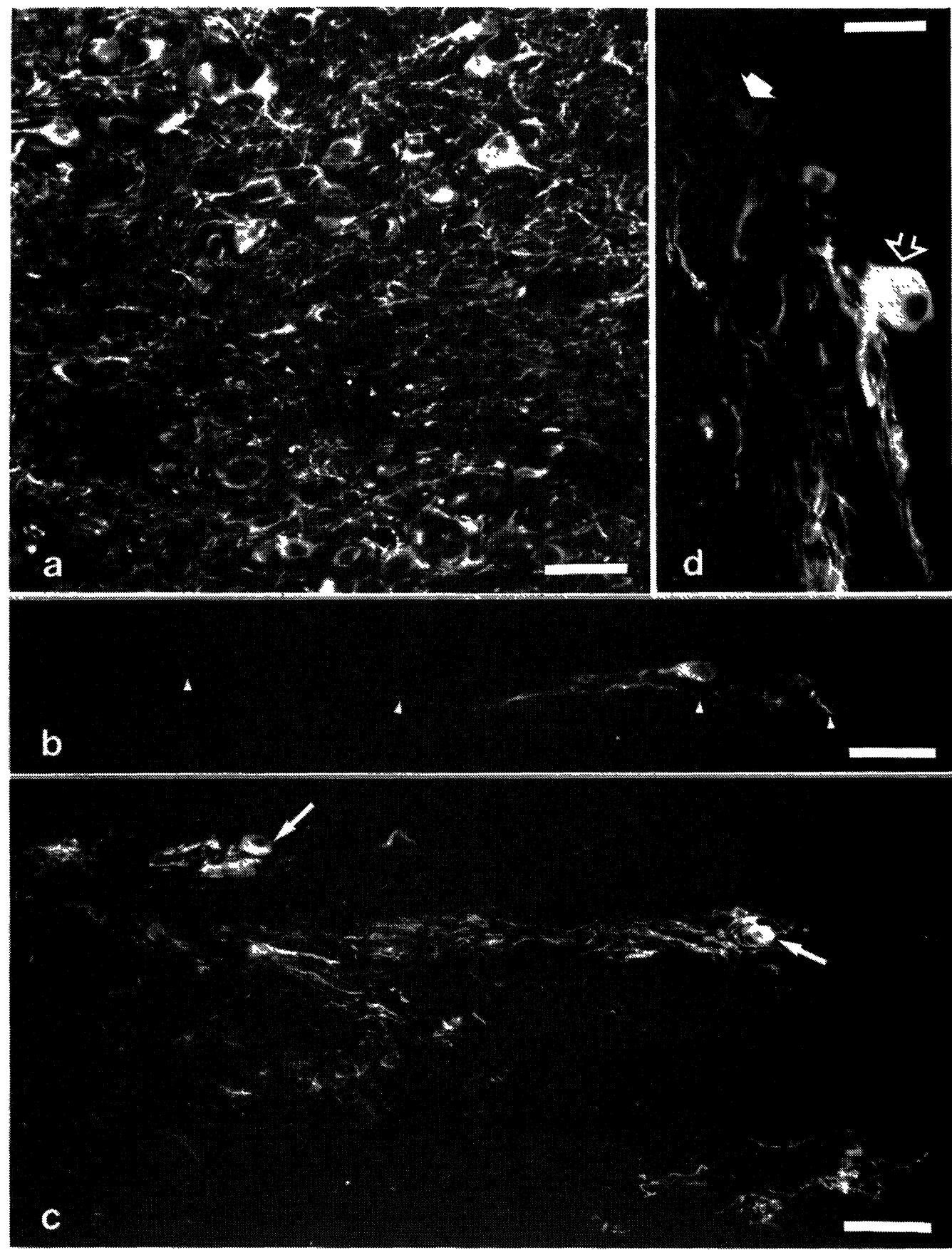

Fig. 5: Somato-dendritic profiles of MAP2 immunoreactivity in short and long term isolated grafts.

(a) Appearance of labeled perikarya and dendrites in a one month old septal graft. The neuropil is tightly packed with processes.

(b) Neuron with bi-directional elongated dendrites (arrowheads) in a two month old substantia nigra graft.

(c) Section of a long term septal graft illustrating the reduction in MAP2 immunoreactivity. Arrows note hypertrophied perikarya. Compare with Fig. $5 \mathrm{a}$.

(d) Abnormal features of MAP2 staining in a one year substantia nigra implant. Open arrow indicates a swollen neuronal cell body. Closed arrow indicates a faintly stained neuron with extensive regression of the dendrite arbor.

Scale bar for Figs. $5 \mathrm{a}, \mathrm{b}$ and $d=50 \mu \mathrm{m}$, for $5 \mathrm{c}=100 \mu \mathrm{m}$ 
study - the perikaryal expression of a high molecular weight phosphorylated neurofilament protein - has been observed both in neurons with axonal damage and in neurons affected by neurodegenerative diseases. Axotomy of nervous system pathways has been explored as a model to determine the types of neurofilament responses subsequent to injury. Several groups have illustrated the abnormal reactivity of neuronal perikarya with axon specific neurofilament antibodies subsequent to axonal damage $/ 18,25,38,48 /$. The change from an axonal to a somata neurofilament distribution after axonal lesions has been suggested to result from alterations in neurofilament phosphorylation rather than from changes in the transport rate of phosphorylated neurofilaments $/ 25 /$. Recently, Koliatsos et al. /34/ have examined cytoskeletal changes in a central cholinergic pathway and reported ectopic perikaryal phosphorylation of neurofilaments in the rat medial septal nucleus following transections of the fimbria-fornix. Unlike these axotomy models, the alterations in neurofilament expression in the present graft system occur without any experimental intervention subsequent to the transplantation.

In neurodegenerative diseases, various phosphoproteins are expressed in the neuronal somata and associate with abnormal inclusions 140,44,52/. Neurons affected by Alzheimer's disease express aberrant phosphorylated neurofilaments in the perikarya /12,54/ and antibodies to phosphorylated neurofilaments define characteristic filamentous accumulations (Lewy bodies) in the somata of substantia nigra neurons in cases of Parkinson's disease /20,22,24/. Cytoskeletal changes in hippocampa neurons of Alzheimer's disease have been hypothesized as markers for the disconnection of and isolation of the hippocampal formation from the limbic and association cortices $/ 30,52 /$.

Another aspect of altered neurofilament staining was noted in axons of only the long term grafts. Many profiles of short, thickened axonal segments that showed kinks or sharp changes in their direction were apparent. Descriptions of axonal disruption and fibers with similar morphology referred to as "kinked" processes have been made in Alzheimer's disease using antibodies to the phosphoprotein tau - an axonal marker /14,31,32/. Duyckaerts et al. /19/ have also examined fiber architecture in 3-dimensional space in sections of Alzheimer neocortex after Bodian impregnation and shown a high correlation of the density of "kinked" fibers with the severity of the disease. Explanations offered for this abnormal cytoarchitecture in Alzheimer's disease include atrophy of the brain tissue, neuronal death and altered physical properties of the fibers in connection with changes in the cytoskeleton /19/. These possible explanations are supported by the appearance of kinked fibers in the present CNS grafts that undergo tissue shrinkage and neuronal death.

\section{Dendrite morphology monitored by MAP2}

The MAP2 antibodies are described as specific, optimal tools to label the entire dendritic fields of nervous tissue /13/. Furthermore, they preclude certain drawbacks of the Golgi impregnation technique such as inconsistency of dendrite impregnation and failure to identify the neurons in question. It is most likely that the MAP2 antibody did show complete dendrite arbors in the present study. For example, the arbor patterns of grafted nigral neurons outlined by the MAP2 antibody resembled horseradish peroxidase filled dopaminergic neurons in the substantia nigra identified by electrophysiological criteria $/ 56 /$.

This protein has been used to evaluate dendritic changes after experimental ischemic damage $/ 33$ / and to monitor arbor morphology in the hippocampus and septum subsequent to lesioning /8/. Results by Cáceres and co-workers /8/ have suggested that MAP2 changes only in neurons in which denervation is accompanied by a significant remodeling of dendrites.

In the aging CNS and in disease, dendrites change in form $/ 11,50 /$. Loss of an afferent input and the death of neighboring neurons are two factors thought to be important in changes of the dendritic trees /10/. Age-related changes in dendrite arbors of the human and rodent brain, identified by the Golgi technique, include swelling of the cell body and dendrites, followed by loss of the dendrite and spine populations /49/. In the present study, aspects of somatodendritic hypertrophy and regression of the arbors were clearly illustrated by MAP2 im- 
munoreactivity in the long term grafts, lending further support to the importance of an appropriate afferent supply and the loss of neurons in regulating the dendritic extent.

\section{Role of targets and trophic factors in cytoskele- tal changes}

The reasons for the cytoskeletal changes in these intra-sciatic CNS grafts are unknown at this time. Inappropriate neural targets and/or inadequate trophic support are two factors that may be primarily associated with the formation of the abnormal cytoskeletal characteristics in the present experiments. This transplant model is amendable to explore these two perspectives.

Evidence that terminal contacts with appropriate targets may be important in normal neurofilament patterns has been obtained from an immunohistochemical study of phosphorylated neurofilament (RT97) staining in long term intracerebral septal transplants $/ 16 /$. In subgroups of septal neurons without apparent axonal connections to the host hippocampus, strong perikaryal labeling to the RT97 antibody was observed. Regions of the grafts with long axonal projections never showed this reversal in neurofilament staining.

Perhaps the closest paradigm to a neural graft isolated within the peripheral nervous system is the intraocular transplant. Grafts of neural and non-neural tissue in the anterior chamber of the eye have been studied extensively by Olson and his colleagues to monitor cellular and trophic interactions between selected tissues /41/. The in oculo CNS preparation has recently been used to examine the effect of a target on cytoskeletal morphology. In one year old intraocular septal transplants, a number of disturbances in immunoreactivity to axonal and dendritic proteins is evident. These cytoskeletal changes in septal neurons can be prevented by co-grafting the septum with the hippocampal formation /17/.

It is also clear that these CNS regions, grafted into the peripheral nerves, are subjected to a variety of chemical factors at concentrations that they would not normally encounter in the CNS. Identified neurotrophic factors, including basic fibroblast growth factor $/ 42 /$, platelet derived growth factor /45/ and nerve growth factor /28/, are all synthesized in sciatic nerves and are ele- vated subsequent to peripheral nerve injury. In short, the diverse variety of substances in peripheral nerve, either alone or in combination, must also be regarded as possible factors involved with the disturbances in cytoskeletal morphology in the present experimental model.

On the other hand, trophic requirements for these CNS grafts may not be sufficient for the PNS to support the neurons on a long term basis. The very early appearance of ectopic neurofilaments in neuronal cell bodies of the septal grafts, but not in substantia nigra or telencephalic grafts $/ 15 /$, indicates that regions of the CNS respond differently on a temporal basis in the PNS. This finding may relate to specific synaptic interactions and CNS trophic factors that are required by subpopulations of central neurons to maintain a normal cytoskeleton.

\section{CONCLUDING REMARKS}

The results have extended the initial findings of cytoskeletal changes in central neurons when grafted into the PNS and have further classified the immunoreactive determinants associated with the aberrant changes. The data presented indicate that the septal and substantia nigra regions of the CNS survive within the peripheral nerve environment. Normal molecular and cellular characteristics are initially expressed by the neurons in these transplants. In the long term, graft shrinkage and gradual neuronal death is accompanied by a series of cytoskeletal changes. Many of the aberrant changes that develop are akin to events in the aging CNS and are similar to degenerative neuronal profiles in specific neurological diseases (Alzheimer's and Parkinson's disease).

Furthermore, this model can be manipulated to investigate possible causative factors in the process of cytoskeletal change under controlled conditions. An approach to examine the conditions that influence the cytoskeleton in these transplants will involve co-grafts of source and target tissues in the peripheral nerves. Experiments currently in progress have animals cografted with substantia nigra and a portion of the adrenal medulla to evaluate possible modulatory effects of a catecholaminergic source on the 
aberrant cytoskeletal characteristics in the intrasciatic nigral graft.

\section{ACKNOWLEDGEMENTS}

This work was supported by grants from the J.P. Bickell Foundation and the Parkinson Foundation of Canada. The author gratefully acknowledges Dr. J.N. Wood for the monoclonal antibody RT97 and Dr. E.M. Johnson Jr. for the affinity purified 192-IgG. Secretarial support from Laura Latimer is also greatly appreciated.

\section{REFERENCES}

1. Aguayo AJ, Björklund A, Stenevi U, Carlstedt T. Fetal mesencephalic neurons survive and extend long axons across peripheral nervous grafts inserted into the adult rat striatum. Neurosci Lett 1984; 45: 53-58.

2. Anderton BH, Breinburg D, Downes MJ, Green PJ, Tomlinson BE, Ulrich J, Wood JN, Kahn J. Monoclonal antibodies show that neurofibrillary tangles and neurofilaments share antigenic determinants. Nature 1982; 298: 84-86.

3. Armstrong DM, Terry RD, Deteresa RM, Bruce G, Hersh LB, Gage FH. Response of septal cholinergic neurons to axotomy. J Comp Neurol 1987; 264: 421436.

4. Bernstein JJ, Viability, growth, and maturation of fetal brain and spinal cord in the sciatic nerve of adult rat. J Neurosci Res 1983; 10: 343-350.

5. Björklund $A$, Stenevi U. Intracerebral neural implants: neuronal replacement and reconstruction of damaged circuitries. Ann Rev Neurosci 1984; 7: 279308.

6. Bruce $\mathrm{C}$, Wainer $\mathrm{BH}$, Hersh LB. Immunoaffinity purification of human choline acetyltransferase: Comparison of the brain and placental enzymes. J Neurochem 1985; 45: 611-620.

7. Cáceres A, Binder LI, Payne R, Bender P, Rebhun L, Steward O. Differential subcellular localization of tubulin and the microtubule-associated protein MAP2 in brain tissue as revealed by immunocytochemistry with monoclonal hybridoma antibodies. J Neurosci 1984; 4: 394-410.

8. Cáceres A, Busciglio J, Ferreira A, Steward O. An immunocytochemical and biochemical study of the microtubule-associated protein MAP2 during postlesion dendritic remodeling in the central nervous system of adult rats. Mol Brain Res 1988; 3: 233-246.

9. Chandler CE, Parsons LM, Hosang M, Shooter EM. A monoclonal antibody modulates the interaction of nerve growth factor with PC12 cells. J Biol Chem 1984; 259: 6882-6889.
10. Coleman PD, Buell SJ. Regulation of dendritic extent in developing and aging brain. In: Cotman CW, ed, Synaptic Plasticity. New York: Guilford Press, 1985; pp. 311-333.

11. Coleman PD, Flood DG. Neuron numbers and dendritic extent in normal aging and Alzheimer's disease. Neurobiol Aging 1987; 8: 521-545.

12. Cork LC, Sternberger NH, Sternberger LA, Casanova MF, Struble RG, Price DL. Phosphorylated neurofilament antigens in neurofibrillary tangles in Alzheimer's disease. J Neuropathol Exp Neurol 1986; 45: 56-64.

13. DeCamilli P, Miller PE, Navone F, Theurkauf WE, Vallee RB. Distribution of microtubule-associated protein 2 in the nervous system of the rat studied by immunofluorescence. Neuroscience 1984; 11: 819-846.

14. Delaère $P$, Duyckaerts C, Brion JP, Poulain V, Hauw J-J. Tau, paired helical filaments and amyloid in the neocortex: a morphometric study of 15 cases with graded intellectual status in aging and senile dementia of Alzheimer type. Acta Neuropathol 1989; 77: 645653.

15. Doering LC, Aguayo AJ. Hirano bodies and other cytoskeletal abnormalities develop in fetal rat CNS grafts isolated for long periods in peripheral nerve. Brain Res 1987; 401: 178-184.

16. Doering LC, Nilsson OG, Björklund A, Aguayo AJ. Possible role of terminal connectivity in the expression of perikaryal immunoreactivity to the monoclonal antibody RT97 in basal forebrain neural grafts. Soc Neurosci Abstr 1987; 13: 163.

17. Doering LC, Eriksdotter-Nilsson M, Olson L. Spatial distributions of cytoskeletal proteins and the NGFreceptor in septal transplants in oculo: Protection from abnormal immunoreactivity by hippocampal cografts. Neuroscience 1991 (in press).

18. Dräger UC, Hofbauer A. Antibodies to heavy neurofilament subunit detect a subpopulation of damaged ganglion cells in retina. Nature 1984; 309: 624-626.

19. Duyckaerts C, Kawasaki H, Delaère P, Rainsard C, Hauw J-J. Fibre disorganization in the neocortex of patients with senile dementia of the Alzheimer type. Neuropathol Appl Neurobiol 1989; 15: 233-247.

20. Forno LS, Sternberger LA, Sternberger NH, Strefling AM, Swanson K, Eng LF. Reaction of Lewy bodies with antibodies to phosphorylated and non-phosphorylated neurofilaments. Neurosci Lett 1986; 64: 253 258.

21. Foster GA, Dahl D, Lee VM-Y. Temporal and topographic relationships between the phosphorylated and nonphosphorylated epitopes of the $200 \mathrm{kDa}$ neurofilament protein during development in vitro. J Neurosci 1987; 7: 2651-2663.

22. Galloway PG, Grundke-Iqbal I, Iqbal K, Perry G. Lewy bodies contain epitopes both shared and distinct from Alzheimer neurofibrillary tangles. J Neuro- 
pathol Exp Neurol 1988; 47: 654-663.

23. Garner CC, Matus A, Anderton B, Calvert R. Microtubule-associated proteins MAP5 and MAP1x: closely related components of the neuronal cytoskeleton with different cytoplasmic distributions in the developing brain. Mol Brain Res 1989; 5: 85-92.

24. Goldman JE, Yen SH, Chiu FC, Peress NS. Lewy bodies of Parkinson's disease contain neurofilament antigens. Science 1983; 221: 1082-1084.

25. Goldstein ME, Cooper HS, Bruce J, Carden MJ, Lee VMY, Schlaepfer WW. Phosphorylation of neurofilament proteins and chromatolysis following transection of rat sciatic nerve. J Neurosci 1987; 7: 1586-1594.

26. Goslin K, Schreyer DJ, Skene JHP, Banker G. Development of neuronal polarity: GAP-43 distinguishes axonal from dendritic growth cones. Nature 1989; 336: 672-674.

27. Haugh MC, Probst A, Ulrich J, Kahn J, Anderton BH. Alzheimer neurofibrillary tangles contain phosphorylated and hidden neurofilament epitopes. J Neural Neurosurg Psychiat 1986; 49: 1213-1220.

28. Heumann $R$, Korsching S, Bandtlow C, Thoenen $H$. Changes of nerve growth factor synthesis in nonneuronal cells in response to sciatic nerve transection. J Cell Biol 1987; 104: 1623-1631.

29. Huber G, Matus A. Differences in the cellular distribution to two microtubule-associated proteins, MAP-1 and MAP-2, in rat brain. J Neurosci 1984; 4: 151-160.

30. Hyman BT, Van Hoesen GW, Damasio AR, Barnes CL. Alzheimer's disease: Cell-specific pathology isolates the hippocampal formation. Science 1984; 225: 1168-1170.

31. Joachim CL, Morris JH, Selkoe DJ, Kosik KS. Tau epitopes are incorporated into a range of lesions in Alzheimer's disease. J Neuropathol Exp Neurol 1987; 46: 611-622.

32. Kowall NW, Kosik KS. Axonal disruption and aberrant localization of tau protein characterize the neuropil pathology of Alzheimer's disease. Ann Neurol 1987; 22: 639-643.

33. Kitagawa $K$, Matsumoto $M$, Niinobe $M$, Mikoshiba $K$, Hata $R$, Ueda $H$, Handa $N$, Fukunaga $R$, Isaka $Y$, Kimura K, Kamada T. Microtubule associated protein 2 as a sensitive marker for cerebral ischemic damage immunohistochemical investigation of dendritic damage. Neuroscience 1989; 31: 401-411.

34. Koliatsos VE, Applegate MD, Kitt CA, Walker LC, DeLong MR, Price DL. Aberrant phosphorylation of neurofilaments accompanies transmitter-related changes in rat septal neurons following transection of the fimbria-fornix. Brain Research 1989; 482: 205-218.

35. Kosik KS, Finch EA. MAP2 and tau segregate into dendritic and axonal domains after the elaboration of morphologically distinct neurites: An immunocytochemical study of cultured rat cerebrum. J Neurosci 1987; 7(10): 3142-3153.
36. Lasek RJ. Studying the intrinsic determinants of neuronal form and function. In: Lasek RJ, Black MM, eds, Intrinsic Determinants of Neuronal Form and Function. New York: Alan R Liss Inc, 1988; pp 3-58.

37. Lee VM-Y, Otvos L Jr, Carden MJ, Hollosi M, Dietzschold B, Lazzarini RA. Identification of the major multiphosphorylation site in mammalian neurofilaments. Proc Natl Acad Sci 1988; 85: 1998-2002.

38. Mansour H, Bignami A, Labkovsky B, Dahl D. Neurofilament phosphorylation in neuronal perikarya following axotomy: A study of rat spinal cord with ventral and dorsal root transection. J Comp Neurol 1989; 283: 481-485.

39. Matus A, Bernhardt $R$, Hugh-Jones $T$. High molecular weight microtubule-associated proteins are preferentially associated with dendritic microtubules in brain. Proc Natl Acad Sci 1981; 78: 3010-3014.

40. Miller C, Haugh M, Kahn J, Anderton B. The cytoskeleton and neurofibrillary tangles in Alzheimer's disease. Trend Neurosci 1986; 9: 76-81.

41. Olson L, Seiger $\AA$, Stromberg I. Intraocular transplantation in rodents. A detailed account of the procedure and examples of its use in neurobiology with special reference to brain tissue grafting. In: Fedoroff S, ed, Advances in Cellular Neurobiology, Vol. 4. New York: Academic Press, 1983; pp 407-442.

42. Otto D, Unsicker K, Grothe C. Pharmacological effects of nerve growth factor and fibroblast growth factor applied to the transectioned sciatic nerve on neuron death in adult rat dorsal root ganglia. Neurosci Lett 1987; 83: 156-160.

43. Peng I, Binder LI, Black MM. Biochemical and immunological analyses of cytoskeletal domains of neurons. J Cell Biol 1986; 102: 252-262.

44. Price DL. New perspectives on Alzheimer's disease. Ann Rev Neurosci 1986; 9: 489-512.

45. Raivich G, Kreutzberg GW. Expression of growth factor receptors in injured nervous tissue, II. Induction of specific platelet-derived growth factor binding in the injured PNS is associated with a breakdown in the blood-nerve barrier and endoneurial interstitial oedema. J Neurocytol 1987; 16: 701-711.

46. Richardson PM, Issa VMK. Transplantation of embryonic spinal and cerebral tissue to sciatic nerves of adult rats. Brain Res 1986; 298: 146-148.

47. Rohrer $\mathrm{H}$, Acheson AL, Thibault J, Thoenen $\mathrm{H}$. Developmental potential of quail dorsal root ganglion cells analyzed in vitro and in vivo. J Neurosci 1986; 6: 2616-2624.

48. Rosenfeld J, Dorman ME, Griffin JW, Sternberger LA, Sternberger NH, Gold BG, Price DL. Distribution of neurofilament antigens after axonal injury. $J$ Neuropathol Exp Neurol 1987; 46: 269-282.

49. Scheibel AB. Structural aspects of the aging brain: Spine systems and the dendritic arbor. In: Katzman R, Terry RD, Bick KL, eds, Alzheimer's Disease: Senile Dementia and Related Disorders. New York: Raven 
Press, 1978; pp 353-373.

50. Scheibel $A B$. The gerohistory of the aging human forebrain: Some structuro-functional considerations. In: Enna SJ et al, eds, Brain Neurotransmitters and Receptors in Aging and Age Related Disorders. New York: Raven Press, 1981; pp 31-41.

51. Seiger $\AA$. Preparation of immature central nervous system regions for transplantation. In: Björklund A, Stenevi U, eds, Neural Grafting in the Mammalian CNS. Amsterdam: Elsevier Science Publishers, 1985; pp 71-77.

52. Selkoe DJ. Deciphering Alzheimer's disease: The pace quickens. Trends Neurosci 1987; 10: 181-184.

53. Sternberger LA, Sternberger NH. Monoclonal antibodies distinguish phosphorylated and non-phosphorylated forms of neurofilaments in situ. Proc Natl Acad Sci USA 1983; 80: 6126-6130.

54. Sternberger NH, Sternberger LA, Ulrich J. Aberrant neurofilament phosphorylation in Alzheimer's disease. Proc Natl Acad Sci USA 1985; 82: 4274-4276.

55. Taniuchi M, Johnson Jr EM. Characterization of the binding properties and retrograde axonal transport of a monoclonal antibody directed against the rat nerve growth factor receptor. J Cell Biol 1985; 101: 11001106.

56. Tepper JM, Sawyer SF, Groves PM. Electrophysiologically identified nigral dopaminergic neurons intracellularly labelled with HRP: Light-microscopic analysis. J Neurosci 1987: 7: 2794-2806.

57. Ulrich J, Probst A, Langui D, Anderton BH, Brion JP. Cytoskeletal immunocytochemistry of Alzheimer's dementia and related diseases. Pathol Immunopathol Res 1987; 6: 273-283.

58. Vallee RB, Bloom GS. High molecular weight microtubule-associated proteins (MAPS). Mod Cell Biol 1984; 3: 21-75. 

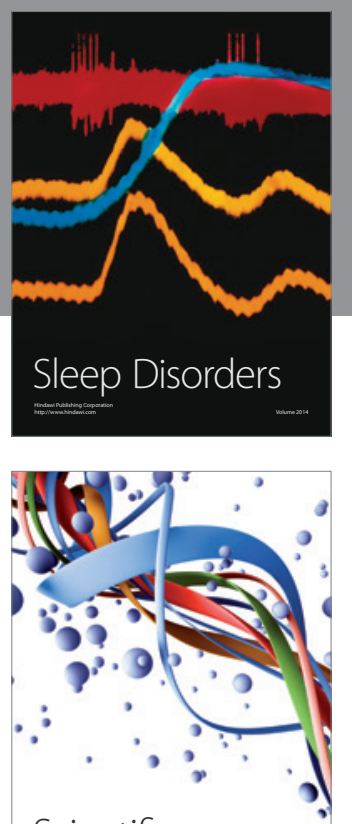

Scientifica
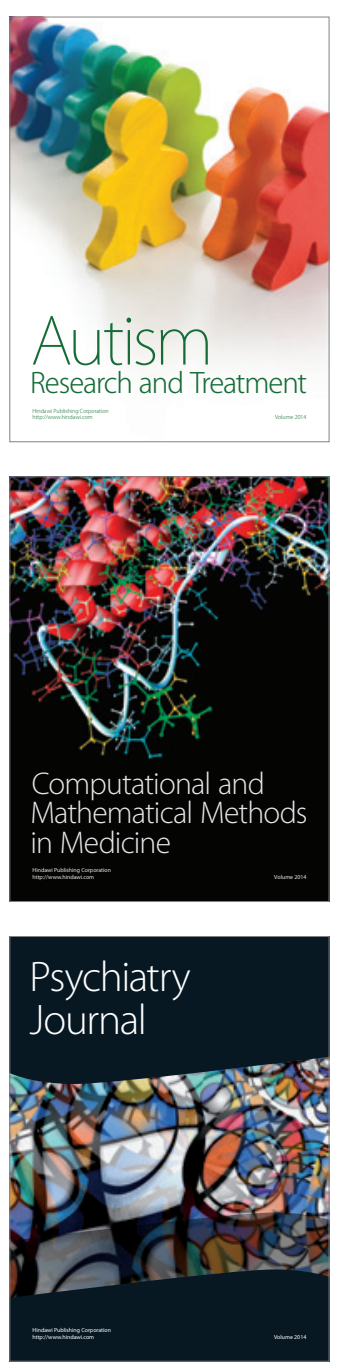
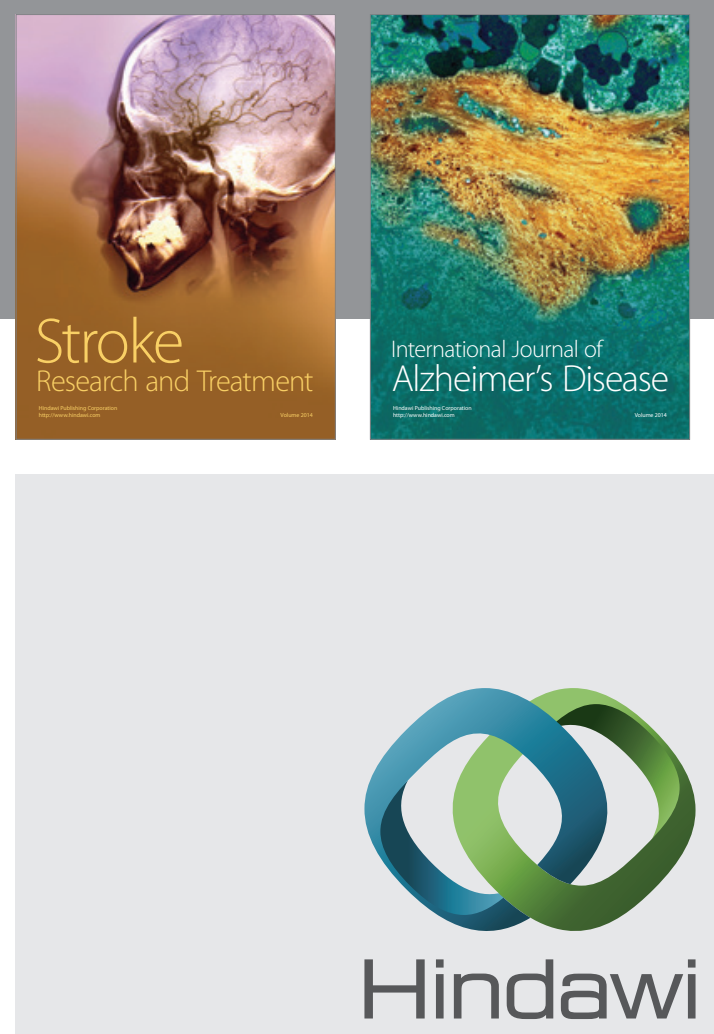

Submit your manuscripts at

http://www.hindawi.com
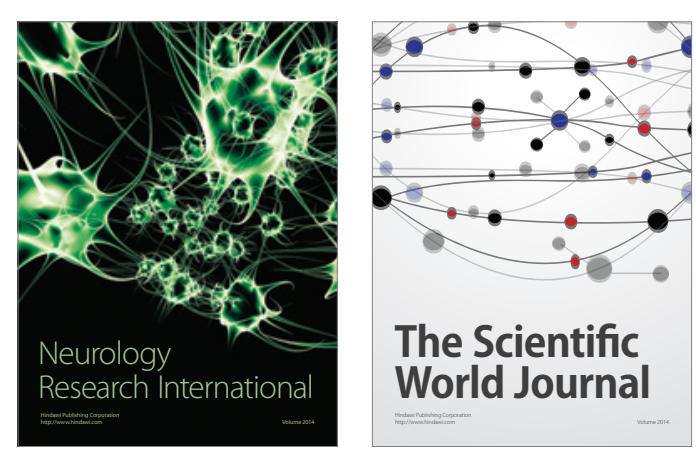

The Scientific World Journal

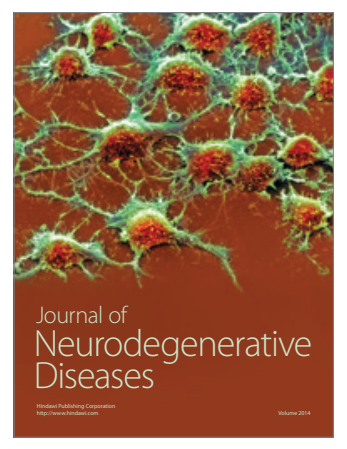

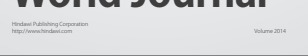

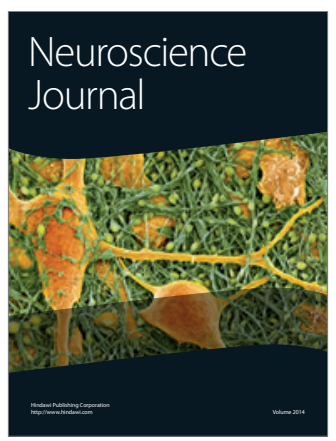

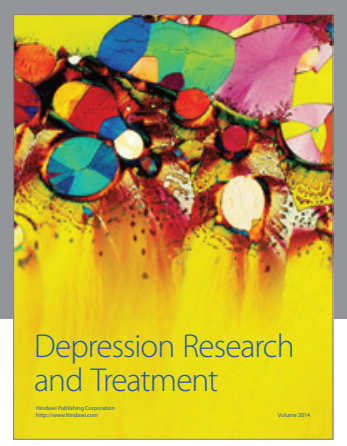
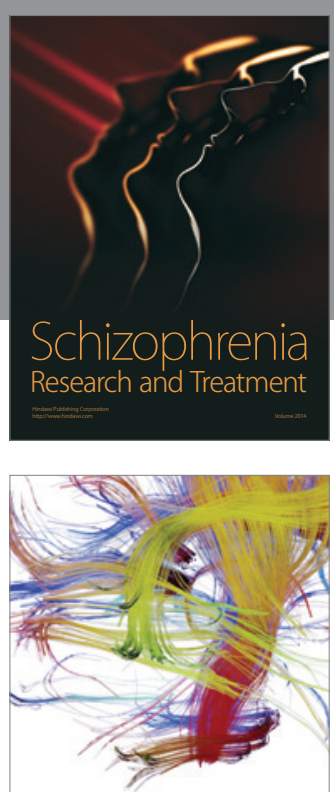

Brain Science

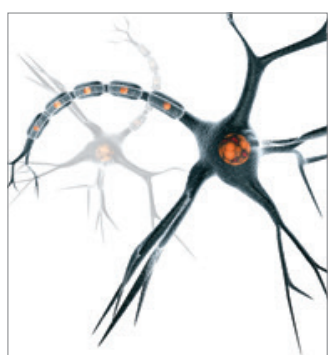

Neural Plasticity
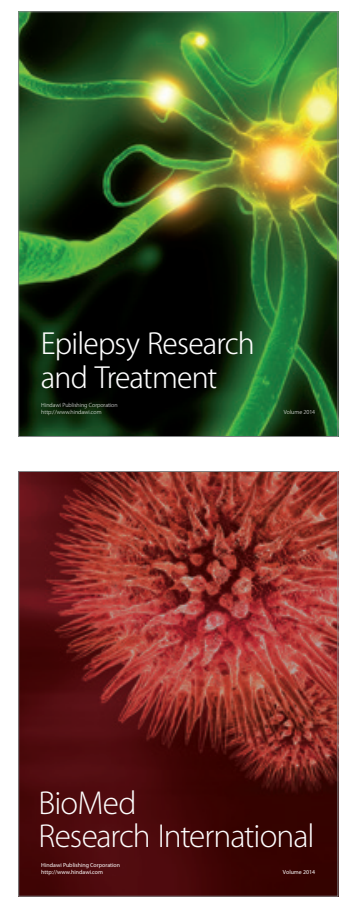

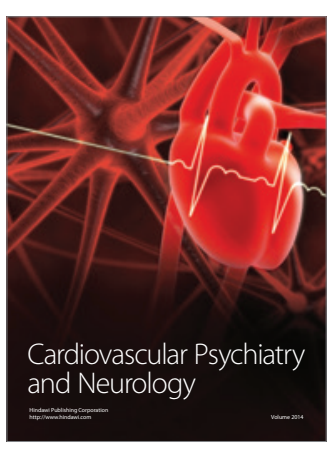

Parkinson's

Disease
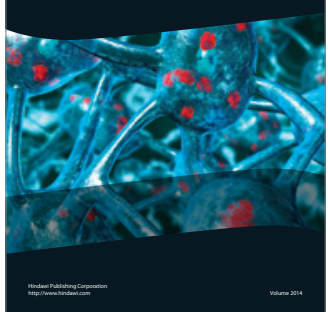